\title{
COVID-19: UMA ABORDAGEM MÉDICO-CONSERVACIONISTA
}

\author{
Rodrigo Grazinoli Garrido \\ Doutor em Ciência pela Universidade Federal Rural do Rio de Janeiro (UFRRJ), \\ Seropédica, RJ, Brasil \\ Professor Adjunto da Universidade Católica de Petrópolis (UCP/PPGD), RJ, Brasil \\ Professor Adjunto da Universidade Federal do Rio de Janeiro (UFRJ/FND), RJ, Brasil \\ grazinoli.garrido@gmail.com \\ Eduardo Leal Rodrigues \\ Mestre em Diversidade Biológica e Conservação pela Universidade Federal de São Carlos \\ (UFSCar), Sorocaba, SP, Brasil \\ Assessor Científico em Identificação Humana da Promega Corporation, São Paulo, SP, Brasil \\ rodrigues.dna@gmail.com
}

\begin{abstract}
RESUMO
Desde o final de 2019, na China, um novo coronavírus passou a provocar síndrome respiratória aguda grave (SARS), que se espalhou pelo mundo e estabeleceu uma pandemia. O surto já acometeu milhões de pessoas, gerou centenas de milhares de mortes e trouxe prejuízo econômico que pode alcançar trilhões de dólares. Vírus, como o agente da COVID-19, passam a infectar o homem por episódios de salto da barreira interespecífica, passando por uma ou mais espécies. Assim, a contaminação inicial depende do contato com a vida selvagem, o que se torna cada vez mais comum com a hiperexploração de espécies, a destruição de habitat e o aumento populacional. $O$ estudo desse fluxo de agentes infecciosos, relacionando a medicina humana à sanidade animal e às questões ambientais, é feito pela Medicina da Conservação. A partir de pesquisa exploratória, analisou-se a COVID-19 através da perspectiva médicoconservacionista, mostrando que intervenções na origem dos agentes infecciosos seriam capazes de restringir surtos devastadores de doenças e, consequentemente, reduzir impactos sociais e econômicos.
\end{abstract}

Palavras-chave: Pandemia. SARS-CoV-2. Medicina da Conservação. Impacto Ambiental. Salto Interespecífico.

\section{COVID-19: A MEDICAL-CONSERVATIONIST APPROACH}

\begin{abstract}
Since the end of 2019, in China, a new coronavirus has been causing severe acute respiratory syndrome (SARS) that has spread around the world and established a pandemic. The outbreak has already affected millions of people, generated hundreds of thousands of deaths and brought economic losses that can reach trillions of dollars. Viruses like the COVID-19 agent can infect humans through episodes of jumping the interspecific barrier, passing through one or more species. Thus, initial contamination depends on contact with wildlife, which is becoming
\end{abstract}


increasingly common with species overexploitation, habitat destruction and population growth. The study of this flow of infectious agents, relating human medicine to animal health and environmental issues is done by Conservation Medicine. Based on exploratory research, COVID19 was analyzed from a medical-conservationist perspective and it was shown that interventions at the origin of infectious agents would be able to restrict devastating outbreaks of diseases and, consequently, reduce social and economic impacts.

Keywords: Pandemic. SARS-CoV-2. Conservation Medicine. Environmental Impact. Spillover. 


\section{INTRODUÇÃO}

A partir dos primeiros relatos da COVID-19 em Wuhan, Província de Hubei, China, diversas discussões têm sido levantadas acerca da origem do novo coronavírus (SARS-CoV-2). Surgiram posições que variavam desde de uma concepção beligerante, na qual o novo coronavírus seria uma arma biológica até a explicação holística, que parte da relação do homem com o meio ambiente. Todavia, a única certeza é que o surto de COVID-19 se transformou em uma pandemia de dispersão mundial, com milhões de casos confirmados e número de mortes na casa de centenas de milhares conforme a World Health Organization (WHO, 2020a). Em paralelo, como era possível prever, a economia mundial apresenta prejuízos nunca antes sofridos, na faixa de trilhões de dólares. (ALEGADO, 2020).

Análises moleculares já demonstraram como o novo coronavírus saltou a barreira interespecífica, passando por, pelo menos, duas outras espécies, até alcançar o homem (KAKODKAR; KAKA; BAIG, 2020). Nesse sentido, há algumas décadas, cunhou-se o termo Medicina da Conservação para relacionar a medicina humana à sanidade animal e às questões ambientais. Essa área vai além do estudo dos reservatórios zoonóticos, considerando a relação mútua e contínua entre todos os componentes do ambiente. Assim, uma abordagem médicoconservacionista pode ajudar a desenvolver medidas preventivas para controle de futuros surtos e mitigar os impactos econômicos com a disseminação de doenças.

O trabalho buscou apresentar a COVID-19 a partir dessa perspectiva da Medicina da Conservação, evidenciando a origem da doença em dinâmicas ambientais que colocam em risco ecossistemas, principalmente a destruição de habitat e superexploração de espécies. Além disso, buscou-se demonstrar como os impactos econômicos poderiam ser reduzidos com esse tipo de abordagem.

Para tanto, desenvolveu-se pesquisa exploratória e descritiva, que pode ser caracterizada como uma revisão sistemática de documentação indireta de fontes primárias da legislação brasileira e de fontes secundárias, como artigos publicados em revistas científicas internacionais indexadas ao Sistema PubMed $^{\circledR}$, bem como aquelas disponibilizadas pelos autores na plataforma ResearchGate ${ }^{\circledR}$. As buscas foram realizadas entre os meses de março e abril de 2020, utilizando-se os termos em português: coronavírus, 2019-nCoV, COVID-19, Medicina da Conservação, Economia e Pandemia, e suas traduções para o inglês. A sistematização da revisão foi a relação da COVID-19 com a abordagem médico-conservacionista 
ou zoonótica. Foram também utilizados relatórios da Organização Mundial de Saúde e do Banco Mundial relacionados ao impacto da COVID-19 e de pandemias em geral.

\section{COVID-19 (SARS-CoV-2)}

Em novembro de 2019 começaram a surgir casos de síndrome respiratória aguda grave em Wuhan, China. O agente etiológico da síndrome emergente era um novo coronavírus, SARSCoV-2 (WU et al., 2020). A doença logo se espalhou e em 30 de janeiro de 2020, o Comitê de Vigilância Internacional para as Doenças Transmissíveis da OMS decretou Emergência de Saúde de Âmbito Internacional, batizando-a definitivamente de COVID-19. (WHO, 2020b; WHO, 2020c).

A COVID-19, apesar de ser uma infecção respiratória que varia de leve à grave, apresenta uma variada sintomatologia, que reúne, entre outros sintomas: febre, tosse, dispneia, mialgia, fadiga, confusão mental, dor de cabeça, dor de garganta, rinorreia, dor no peito, diarreia, náusea, vômito e síndrome do desconforto respiratório agudo (DENIS et al., 2020). Os três primeiros são os mais comumente relatados, mas pacientes podem apresentar diferentes graus dos outros, acrescidos de, p.ex., perda do olfato e do paladar. (BRANN et al., 2020).

Como os sintomas mostrarem-se comuns a outras síndromes respiratórias, o diagnóstico tem sido feito através da observação clínica (CHAN et al., 2020), pois há falta de kits de diagnóstico por todo o mundo. A piora no prognóstico pode ser monitorada com o auxílio, p.ex., de imagens tomográficas do pulmão (GUAN et al., 2020) e por análises laboratoriais, como variações no leucograma (LI et al., 2020; CHAN et al., 2020) e nos parâmetros de coagulação e bioquímicos. (LIU et al., 2020).

A certeza da infecção pelo SARS-CoV-2 é possível, logo no início da infecção, pelo teste molecular de Reação em Cadeia da Polimerase-Transcriptase Reversa (RT-PCR). Contudo, essa análise é mais demorada e requer estrutura laboratorial complexa. Por outro lado, os testes rápidos que buscam detectar a resposta imune ao vírus podem ser realizados in loco, com kits para Imunoglobulina M e Imunoglobulina G (IgM e IgG). A IgM surge como resposta à infecção, entre 3-6 dias, enquanto a infecção está ativa. Já a IgG surge tardiamente, em torno de 8 dias, como resposta aparentemente protetora. (LI et al., 2020). 
A taxa de mortalidade é maior em faixa etária mais alta, principalmente após os 50 anos (1,3\%), alcançando $14,8 \%$ em pacientes maiores de 80 anos, independentemente de comorbidades. Mas, não se pode desconsiderar o resultado fatal em pessoas de todas as idades (NOVEL CORONAVIRUS PNEUMONIA EMERGENCY RESPONSE EPIDEMIOLOGY TEAM, 2020). Em muitos casos de óbito, observavam-se comorbidades $(76,8 \%)$ : hipertensão $(56,1 \%)$, doença cardíaca $(20,7 \%)$, diabetes $(18,3 \%)$, doença cerebrovascular $(12,2 \%)$ e câncer $(7,3 \%)$. (FENG et al., 2020).

Como vírus respiratório, o novo coronavírus coloniza em alto grau as vias aéreas superiores. Com isso, a transmissão através da aerossolização do SARS-CoV-2 em espaço confinado ou no ambiente próximo a pessoas infectadas, sintomáticas ou não, e ainda pelo contato a objetos contaminados, parece ser a principal forma (CAl et al., 2020). Determinou-se que o agente pode permanecer infeccioso em aerossóis por até três horas e em superfícies, por até três dias (VAN DOREMALEN et al., 2020). Todavia, o novo coronavírus é inativado pela limpeza com álcool (62-71\%), peróxido de hidrogênio (0.5\%) ou hipoclorito de sódio (0.1\%) (KAMPF et al., 2020). Para a antissepsia, especialmente de mãos e antebraços, água e sabão parecem ser suficientes.

Apesar de muitas pesquisas em andamento, ainda não se tem um medicamento eficaz contra o SARS-CoV-2 (LU, 2020). Vários fármacos já utilizados contra HIV/AIDS e outras patologias, já foram propostos e são associados a antibióticos e anticoagulantes (NEGRI et al., 2020). Os sintomas iniciais podem ser manejados com o uso de anti-inflamatórios não esteroidais (DENIS et al., 2020). Da mesma forma, a busca por imunoprevenção tem estimulado muitos estudos acompanhados pela OMS (WHO, 2020c). A proposta de uso do soro contendo imunoglobulina de convalescentes tem ganhado força como tratamento da doença. (CASADEVALL; PIROFSKI, 2020).

$\mathrm{Na}$ ausência de vacinas para a prevenção ou de uma terapêutica farmacológica adequada à cura, o enfrentamento ao surto da COVID-19, tem requerido medidas clássicas de saúde pública. Entre essas práticas, encontramos a quarentena e o isolamento à contenção social, que têm como função impedir a propagação da doença entre pessoas, interrompendo a transmissão do SARS-CoV-2. (GARRIDO; GARRIDO, 2020). 


\section{CORONAVÍRUS}

O agente etiológico da COVID-19 é um novo coronavírus (SARS-CoV-2). Os coronavírus são conhecidos desde a década de 1960 e originalmente, causavam patologias respiratórias com sintomas de resfriado. Em 2003, contudo, representantes dessa família de vírus geraram um significativo número de casos da síndrome respiratória aguda grave (SARS-CoV), considerada uma doença emergente. (WU et al., 2020).

Os Coronavírus, cujo nome deriva de sua morfologia similar à uma coroa, devido às espículas em seu envoltório (ALMEIDA et al., 1968), são uma família de vírus RNA simples fita e envelopados classificados dentro da ordem Nidoviral (MCINTOSH, 1974). Esta família consiste em patógenos de diversas espécies de animais (tabela 1), divididos em três grupos com base em testes sorológicos (GONZÁLEZ et al., 2003), corroborados por dados genômicos (INTERNATIONAL COMMITTEE ON TAXONOMY OF VIRUSES, 2020), incluindo o SARS-CoV-2, o sétimo coronavírus conhecido a infectar humanos. (WEISS; NAVAS-MARTIN, 2005).

O genoma do SARS-CoV-2 é composto por RNA e tais genomas possuem um gene essencial denominado de RNA Polimerase RNA-dependente ( $R d N p$ ), que possui uma sequência bem conservada entre diferentes vírus. Tal característica torna o gene útil para mensurar a distância evolutiva entre vírus. O grupo de trabalho sobre o coronavírus do International Committee on Taxonomy of Viruses identificou que há poucas diferenças no gene RdRp quando comparando os genomas de SARS-Cov e SARS-CoV-2 em relação a outras variantes como o da MERS, de forma que se evidencia que estes são relacionados geneticamente (GORBALENYA et al., 2020). Contudo, o RNA viral como um todo possui uma taxa de mutação elevada que resulta em variantes virais a cada ciclo de replicação do genoma viral. Isto cria uma população com genomas diversos, conhecido como quasiespécie. Assim, a cada ciclo de replicação viral, as diferenças se acumulam entre o genoma viral original e as progênies virais, podendo contribuir para diferenças no quadro clínico. (YAO et al., 2020).

Tabela 1: Relação de hospedeiros, patogenia e receptor celular associado aos coronavírus (ND = Não Determinado).

\begin{tabular}{|c|c|c|c|c|}
\hline Grupo & Virus & $\begin{array}{c}\text { Hospedeir } \\
\text { o }\end{array}$ & Doença causada & Receptor Celular \\
\hline $\mathrm{I}$ & $\begin{array}{l}229 \mathrm{E} \\
\text { TGEV }\end{array}$ & $\begin{array}{l}\text { Humano } \\
\text { Porco }\end{array}$ & $\begin{array}{l}\text { Infecção Respiratória } \\
\text { Infecção Respiratória e }\end{array}$ & $\begin{array}{l}\text { Aminopeptidase Humana } \\
\text { Aminopeptidase suína }\end{array}$ \\
\hline
\end{tabular}




\begin{tabular}{|c|c|c|c|c|}
\hline & & & Entérica & \\
\hline & PRCoV & Porco & Infecção Respiratória & $\begin{array}{l}\text { Aminopeptidase } \\
\text { Suína }\end{array}$ \\
\hline & $\begin{array}{l}\text { Coronavirus } \\
\text { canino }\end{array}$ & Cão & Infecção Entérica & $\begin{array}{l}\text { Aminopeptidase } \\
\text { Canina }\end{array}$ \\
\hline & $\mathrm{FeCoV}$ & & Infecção Entérica & $\begin{array}{l}\text { Aminopeptidase } \\
\text { Felina }\end{array}$ \\
\hline & FIPV & Gato & $\begin{array}{l}\text { Infecção entérica, } \\
\text { respiratória e neurológica e } \\
\text { hepatite }\end{array}$ & $\begin{array}{l}\text { Aminopeptidase } \\
\text { Feline }\end{array}$ \\
\hline & NL-63 & Humano & Infecção respiratória & $\begin{array}{l}\text { Enzima conversora de } \\
\text { angiostensina } 2 \text { (ACE2) }\end{array}$ \\
\hline II & OC43 & Humano & $\begin{array}{l}\text { Infecção respiratória e } \\
\text { entérica }\end{array}$ & 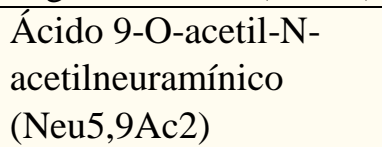 \\
\hline & MHV & $\begin{array}{l}\text { Camundon } \\
\text { go }\end{array}$ & $\begin{array}{l}\text { Infecção neurológica e } \\
\text { entérica e hepatite }\end{array}$ & $\begin{array}{l}\text { Molécula de adesão I } \\
\text { (CEACAM1) }\end{array}$ \\
\hline & $\begin{array}{l}\text { Coronavírus de } \\
\text { sialodacrioadenite }\end{array}$ & Rato & Infecção neurológica & Não Determinado \\
\hline & $\begin{array}{l}\text { Vírus da } \\
\text { encefalomiocardit } \\
\text { e hemaglutinante }\end{array}$ & Porco & $\begin{array}{l}\text { Infecção neurológica, } \\
\text { respiratória e entérica }\end{array}$ & $\begin{array}{l}\text { Ácido 9-O-acetil-N- } \\
\text { acetilneuramínico } \\
(\mathrm{Neu} 5,9 \mathrm{Ac} 2)\end{array}$ \\
\hline & $\mathrm{BCoV}$ & Vaca & Infecção entérica & $\begin{array}{l}\text { Ácido 9-O-acetil-N- } \\
\text { acetilneuramínico } \\
(\mathrm{Neu} 5,9 \mathrm{Ac} 2)\end{array}$ \\
\hline & HKU1 & Humano & Infecção respiratória & \\
\hline & SARS-CoV & Humano & $\begin{array}{l}\text { Síndrome respiratória } \\
\text { aguda }\end{array}$ & $\begin{array}{l}\text { Enzima conversora de } \\
\text { angiostensina } 2 \text { (ACE2) }\end{array}$ \\
\hline III & IBV & Galinha & $\begin{array}{l}\text { Infecção respiratória, } \\
\text { hepatite }\end{array}$ & Não Determinado \\
\hline & $\begin{array}{l}\text { Coronavirus de } \\
\text { peru }\end{array}$ & Peru & $\begin{array}{l}\text { Infecção entérica e } \\
\text { respiratória }\end{array}$ & Não Determinado \\
\hline
\end{tabular}

Fonte: Extraído e adaptado de Weiss e Navas-Martin, 2005.

Ainda em 3 de janeiro de 2020, foi sequenciado o genoma completo do SARS-CoV-2 a partir da amostra de fluido bronquioalveolar de um paciente de Wuhan (TAN et al., 2020). A inserção desse novo coronavírus nas células humanas é mediada pela interação com o receptor ACE2 (hACE2, Enzima conversa de angiostesina 2) com afinidade comparável de isolados virais da epidemia de SARS dos anos de 2002 e 2003 (WALLS et al., 2020). Tendo em vista estudos estruturais e bioquímicos (WAN et al., 2020; WALLS et al., 2020; WRAPP et al., 2020; ZHOU et al., 2020), SARS-CoV-2 aparenta ter uma ligação otimizada para o receptor humano ACE2; e as espículas protéicas de SARS-CoV-2 possuem um sítio de clivagem polibásico funcional no limite entre as subunidades S1-S2 por meio da inserção de 12 nucleotídeos (WALLS et al., 2020). Desta forma, tal modificação tende a contribuir para um maior tropismo e, assim, capacidade 
do SARS-CoV-2 infectar determinado tipo de célula ou tecido, como já relatado para vírus influenza altamente patogênico, na influenza aviária e na doença de Newcastle. (KLENK et al., 1994; STEINHAUER, 1999).

A origem do SARS-CoV-2 a partir da manipulação genética de outras linhagens de SARS-CoV é desconsiderada (ANDERSEN et al., 2020), haja vista que se houvesse sofrido manipulação, um dos diversos sistemas de transcrição reversa teria sido usado (CUI; LI; SHI, 2019). A explicação quanto à origem proposta por Andersen et al. (2020) tem como base dois cenários atribuídos a eventos de seleção natural.

Seleção natural em um organismo animal antes da transferência zoonótica;

Seleção natural em humanos após a transferência zoonótica.

Através de análises moleculares de similaridade do genoma entre amostras virais de que infectam algumas espécies, propôs-se que o SARS-CoV-2 vem sofrendo mutações e, assim, adaptando-se desde seus hospedeiros originais, morcegos, passando por hospedeiros intermediários, pangolim, até chegar em humanos. Relações zoonóticas semelhantes também foram verificadas nos coronavírus da MERS-2012, em que o hospedeiro intermediário eram camelos, e na SARS-2002, na qual o intermediário eram civetas. (KAKODKAR; KAKA; BAIG, 2020).

A compreensão plena sobre como um vírus supera a barreira interespecífica e infecta humanos é uma das ferramentas para prevenção da emergência de novas doenças. No entanto, a taxa de evolução viral e os diversos tipos de vírus existentes nos variados animais tornam a ação preventiva mais complexa. Além disso, comércio não regulado e tráfico de animais tendem a expor seres humanos a vírus desconhecidos (CUI; LI; SHI, 2019). Por isso, a prevenção pela conservação das espécies e de seus habitat, reduzindo o contato do humano à vida selvagem, parece ser a estratégia mais adequada.

\section{IMPACTOS ECONÔMICOS}

Surtos de novos agentes zoonóticos ocorrem a todo momento, com maior ou menor dispersão e, além das consequências à saúde, trazem prejuízos econômicos importantes. Por exemplo, estimou-se que o surto de SARS custou à China entre 12,3 bilhões e 28,4 bilhões, com estimativa de que o PIB tenha caído $2 \%$ no segundo trimestre de 2003 e $1 \%$ durante todo o ano. Ao mesmo tempo, a perda econômica global foi estimada entre 30 bilhões e 100 bilhões de 
dólares (QIU et al., 2018). Em cálculos mais exatos, a SARS causou mais de 700 mortes e perda de US\$ 50 bilhões para a economia global em 2003 (DASZAK et al., 2004). Na epidemia de SARS, em 2003, houve redução no consumo pela paralisia de comércio em Hong Kong e Singapura e impactos na cadeia global de suprimentos diversos, com destaque para a paralisia de atividades na indústria chinesa.

Tais perdas econômicas podem chegar ao setor agropecuário, haja vista que $60 \%$ dos surtos são zoonoses e diversos outros setores como o setor de turismo (WORLD BANK GROUP, 2019). Em uma análise linear pelo número de mortes (WHO, 2020a), com a COVID-19, os valores já poderiam ser multiplicados por centenas de vezes. Na verdade, as projeções do mercado financeiro já apontam um custo maior do que US\$ 4,1 trilhões para a economia global (ALEGADO, 2020). Destaca-se que em ambos os casos de SARS, em 2003 e na atual, a origem estava na vida selvagem.

Sem dúvida, o impacto mais relevante de pandemias são as perdas de vidas e o sofrimento gerado. No entanto, não há como desconsiderar o impacto econômico pelo isolamento social, fechamento de algumas atividades e o próprio aumento de gastos do sistema de saúde. (BLOOM; CARDARETTE; SEVILLA, 2018; DELIVORIAS; SCHOLZ, 2020).

Fan, Jamison e Summers (2018) argumentam que o investimento no preparo contra epidemias nunca é suficiente, mais um motivo para se trabalhar na origem do surto. Os autores calcularam as perdas em uma hipotética epidemia de influenza que levasse a 720.000 mortes/ano, totalizando uma perda econômica em torno de US\$ 500 bilhões por ano. Valor proporcional ao informado para a SARS em 2003. (DASZAK et al., 2004).

Independentemente da amplitude dos impactos nos diversos setores da economia, em surtos epidêmicos e pandêmicos, as principais instituições impactadas estão associadas ao sistema de saúde. No cenário latino americano, em 2017, um relatório emitido pelo United Nations Development Programme (UNDP) em parceria com o International Federation of Red Cross and Red Crescent Societies (IFRC) estimou uma perda econômica de US\$ 7-18 bilhões com a epidemia de Zika. (UNDP, 2017).

Por outro lado, o investimento em ações de conservação ambiental possui um elevado retorno sobre o investimento na forma de bens e serviços ambientais, agregando crescimento econômico local e evitando custos com infraestrutura (BAKER; MACDONALD, 2004). Dados do Land and Water Conservation Fund (LWCF, 2010) tem estimado o retorno de US\$ 4 para cada US\$ 1 investido em conservação ambiental. Contudo, na perspectiva proposta, além de 
esforços diretos na conservação do meio ambiente, fazem-se também necessárias medidas de combate ao tráfico animal e comércio sem regulação sanitária, haja vista que alguns surtos importantes (SARS e Ebola) são oriundos do consumo de itens da vida selvagem. (GE et al., 2013).

Estratégias globalmente coordenadas para combater pandemias, semelhantes às traçadas atualmente no que se refere às mudanças climáticas, são amplamente adaptáveis, na medida em que tentam reduzir o impacto de um patógeno antes da disseminação da doença (JONES et al., 2008). Pike et al. (2014), Cunningham, Daszak e Wood (2017), por meio de revisões e modelagem demonstraram a viabilidade econômica de políticas de medicina da conservação, uma vez que a maioria das pandemias tem origem animal. Assim, novos eventos de surtos ocorrerão, no entanto, podem ser desenvolvidas estratégias de mitigação relacionadas à Medicina da Conservação, reduzindo os fatores subjacentes às pandemias, sobretudo os ambientais que limitam o salto interespécies.

A verdade é que apesar dos avanços médicos, as doenças infecciosas ainda permanecem presentes na sociedade moderna. Algumas regiões, como o norte do Brasil e da África, apresentam doenças endêmicas, como a malária, contudo, outras infecções têm elevado a sua distribuição geográfica, tornando-se epidêmicas e pandêmicas, como a atual síndrome respiratória, COVID-19 (WAN et al., 2020; WALLS et al., 2020). Desde o surto de ebola (20132016) na África Ocidental, grupos influentes, como o World Group Bank, argumentam que ainda há lacunas no preparo de métodos e estruturas de enfrentamento de epidemias e pandemias e defendem maior investimento pautados nos impactos no cenário macroeconômico. (WORLD BANK GROUP, 2019).

Os impactos de tais epidemias na economia são devastadores (SANDS et al., 2016), especialmente em serviços como transporte, turismo, hotelaria, alimentação e entretenimento. A incompatibilidade entre oferta e demanda no mercado causada por doenças infecciosas levou a enormes consequências no emprego (LEE; WARNER, 2006). A incerteza sobre o futuro das epidemias e o medo de sua disseminação internacional certamente reduzirão confiança no desenvolvimento econômico. (SMITH, 2006). 


\section{A PERSPECTIVA MÉDICO-CONSERVACIONISTA}

A Medicina da Conservação é um campo interdisciplinar que tem como horizonte a percepção de que não há como desvincular a saúde humana da saúde animal e da integridade dos ecossistemas (ALDERS, 2009). Esta área surgiu exatamente em resposta a questões de saúde complexas nas últimas décadas, em que os diversos componentes do ambiente mostraram-se vinculados, em especial homens e outros animais. Entre microrganismos tipicamente presentes em animais que acometeram humanos estão: influenza aviária enterovírus E-70 e arbovírus da Febre do Nilo. (SILVEIRA; D’ELIA, 2014).

Na verdade, a proximidade cada vez maior entre humanos e animais, especialmente selvagens, mantém um fluxo contínuo de agentes com diferentes níveis de patogenicidade (SILVEIRA; D'ELIA, 2014, p. 23). Esses patógenos podem adaptar-se ao novo hospedeiro com consequências imprevisíveis na patogenicidade e virulência. De acordo com Silveira e D'Elia (2014, p. 24), esse fluxo de patógenos é incrementado pelo aumento da população humana; desmatamento e avanço do espaço urbano sobre ambientes naturais; aumento do turismo ecológico internacional; coabitação entre espécies nativas e cultivadas devido à intensificação da agricultura e pecuária; negligência epidemiológica no trânsito, translocação e soltura de animais selvagens.

Tanto o surto de 2003, quanto a COVID-19 mostraram que os vírus nas fontes zoonóticas podem cruzar a barreira interespecífica e infectar humanos (LI et al. 2005; CHAN et al., 2020). Nesses casos, a emergência das doenças tem como causa a exposição humana ao vírus através da comercialização ou consumo dos animais infectados. Outra doença infecciosa, a causada pelo vírus da influenza aviária A (H7N9), identificada em março de 2013 na China, mostrou exposição humana a aves vivas ou ambientes potencialmente contaminados, onde as aves vivas foram vendidas. A maior parte do risco de infecção zoonótica foi associada à ingestão e comercialização de animais selvagens, o que pode representar uma ameaça significativa à saúde global e ao desenvolvimento socioeconômico.

Regulamentar a conservação da vida selvagem e a segurança alimentar para impedir a exposição humana a novos vírus é de importância global. No Brasil, em janeiro de 2020, a Secretaria de Vigilância em Saúde do Ministério da Saúde, através do Boletim Epidemiológico 03 (BRASIL, 2020), notificou um paciente do estado de São Paulo infectado por um vírus do gênero Mammarenavirus (família arenaviridae), com 90\% de similaridade com o vírus Sabiá. O 
paciente foi atendido por, pelo menos, três estabelecimentos de saúde entre os municípios de Eldorado, Pariquera-Açu e São Paulo. A origem do vírus parece ser de roedores silvestres. Cabe ressaltar que os vírus da família arenaviridae são classificados como agentes altamente infecciosos de biossegurança 4.

Além disso, no contexto específico da COVID-19, deveria ser acrescida a negligência sanitária no consumo, em especial alimentício, de animais silvestres. Especificamente doenças causadas por coronavírus como SARS-CoV e MERS-CoV parecem ter sido originadas em morcegos e estas infecções transmitidas diretamente ao ser humano por meio de mercados de produtos diversos, principalmente de origem animal e sem regulação sanitária (WEISS; NAVASMARTIN, 2005; GE et al., 2013; WANG et al., 2013).

Assim, além das medidas de prevenção e controle recomendadas pela OMS, ações regulatórias mais eficientes devem ser tomadas para prevenção na fonte e políticas de conscientização social dos perigos e ilegalidade em comercializar e se alimentar com animais selvagens. No Brasil, a Lei 9605/98 (BRASIL, 1998) dispõe sobre sanções penais para crimes cometidos contra o patrimônio ambiental. A atual lei foi formulada com o objetivo de proteger a fauna terrestre e aquática silvestre nativa ou em rota migratória, em especial daquela ameaçada de extinção. Embora, apresente um rol significativo de condutas proibidas, como a caça, a pesca, a matança, a compra, o adquirimento, o transporte, a guarda, a exposição, a exportação e a venda desses animais e de produtos e subprodutos dos mesmos, a lei não é expressa sobre o consumo de animais silvestres.

A percepção de que há relação direta entre ações de desenvolvimento sustentável e a saúde humana é imperativa. Assim, são necessárias políticas estratégicas e multissetoriais com base na medicina da conservação, associadas à preservação da vida silvestre e dos habitat, à vigilância epidemiológica, além de ações de educação ambiental para se evitar novas doenças emergentes e reemergentes.

\section{CONSIDERAÇÕES FINAIS}

O SARS-CoV-2 tem sua origem em um hospedeiro de vida selvagem e, por meio do salto interespecífico, alcançou o homem. Este tipo de mecanismo adaptativo propicia a emergência e reemergência de diversas doenças e se torna cada vez mais comum, em virtude 
da hiperexploração de espécies, da degradação de habitat para atender à agropecuária e à urbanização crescente.

No caso da COVID-19, o contato com os hospedeiros intermediários parece ter-se dado através do consumo de animais exóticos em mercados sem o devido controle sanitário. Assim, a COVID-19 pode ser analisada à luz da medicina da conservação, estudando o fluxo de agentes infecciosos entre animais e humanos influenciado pela degradação ambiental e pela carência sanitária. Nessa perspectiva, o investimento em prevenção, detecção, contenção e resposta no nível de conservação ambiental, levaria a redução na frequência de surtos de doenças emergentes e reemergentes e no impacto social e econômico.

\section{REFERÊNCIAS}

ALDERS, R. Conservation medicine. Environment Science and Policy for Sustainable Development, [S. I.], v. 51, n. 4, p. 7-8, 2009.

ALEGADO, S. Global cost of coronavirus may reach $\$ 4.1$ trillion, ADBsays. Bloomberg, [S. I.], 2020. Disponível em: https://www.bloomberg.com/news/articles/2020-04-03/global-cost-ofcoronavirus-could-reach-4-1-trillion-adb-says. Acesso em: 22 abr. 2020.

ALMEIDA, J. D. et al. Virology: coronavirus. Nature, [S. I.], v. 220, p. 650, 1968.

ANDERSEN, G. A. et al. The proximal origin of SARS-CoV-2. Nature Medicine, [S. I.], v. 26, p. 450452, 2020. DOI 10.1038/s41591-020-0820-9. Disponível em:

https://www.nature.com/articles/s41591-020-0820-9. Acesso em: 1 abr. 2020.

BAKER, Tim; MACDONALD, Laurie. Investing in nature: the economic benefits of conserving natural areas in northeast Florida. Washington: Defenders of Wildlife, 2004. Disponível em: https://defenders.org/sites/default/files/publications/investing_in_nature.pdf. Acesso em: 28 abr. 2020.

BLOOM, D. E.; CARDARETTE, D.; SEVILLA, J. P. The economic risks and impacts of epidemics. F\&D Magazine, [S. I.], v. 55, n. 2, p. 46-49, 2018.

BRANN, David H. et al. Non-neuronal expression of SARS-CoV-2 entry genes in the olfactory system suggests mechanisms underlying COVID-19-associated anosmia. BioRxiv, [S. I.], p. 1-51, 2020. DOI 10.1101/2020.03.25.009084. Disponível em:

https://www.biorxiv.org/content/10.1101/2020.03.25.009084v4. Acesso em: 22 abr. 2020.

BRASIL. Lei no 9.605, de 12 de fevereiro de 1998. Dispõe sobre as sanções penais e administrativas derivadas de condutas e atividades lesivas ao meio ambiente, e dá outras providências. Brasília, DF: Presidência da República, 1998. 
BRASIL. Ministério da Saúde. Boletim epidemiológico: identificação de um caso de febre hemorrágica brasileira no estado de São Paulo, Janeiro de 2020. Brasília, DF: Secretaria de Vigilância em Saúde, 2020. Disponível em:

http://saude.gov.br/images/pdf/2020/janeiro/20/Boletim-epidemiologico-SVS-03.pdf. Acesso em: 25 abr. 2020.

CAI, J. et al. Indirect virus transmission in cluster of COVID-19 cases, Wenzhou, China, 2020. Emerging Infectious Diseases, [S. I.], v. 26, n. 6, p. 1343-1345, 2020. DOI 10.3201/eid2606.200412. Disponível em: https://wwwnc.cdc.gov/eid/article/26/6/200412_article. Acesso em: 22 abr. 2020.

CASADEVALL, A.; PIROFSKI, L. The convalescent sera option for containing COVID-19. The Journal of Clinical Investigation, [S. I.], v. 130, n. 4, p. 1545-1548, 2020. DOI 10.1172/JCI138003. Disponível em: https://www.jci.org/articles/view/138003. Acesso em: 22 abr. 2020.

CHAN, J. F. W. et al. A familial cluster of pneumonia associated with the 2019 novel coronavirus indicating person-to-person transmission: a study of a family cluster. The Lancet, [S. I.], v. 395, p. 514-523, 2020. DOI 10.1016/S0140-6736(20)30154-9. Disponível em: https://www.thelancet.com/pdfs/journals/lancet/PIIS0140-6736(20)30154-9.pdf. Acesso em: 22 abr. 2020.

CUI, J.; LI, F.; SHI, Z. L. Origin and evolution of pathogenic coronaviruses. Nature Reviews Microbiology, [S. I.], v. 17, p. 181-92, 2019.

CUNNINGHAM, A. A.; DASZAK, P.; WOOD, J. L. N. One health, emerging infectious diseases and wildlife: two decades of progress? Philosophical Transactions of the Royal Society B: Biological Sciences, [S. I.], v. 372, n. 1725, 2017. DOI 10.1098/rstb.2016.0167. Disponível em: https://royalsocietypublishing.org/doi/10.1098/rstb.2016.0167. Acesso em: 22 abr. 2020.

DASZAK, P. et al. Conservation medicine and a new agenda for emerging diseases. Annals of the New York Academy of Sciences, [S. I.], v. 1026, p. 1-11, 2004. DOI 10.1196/annals.1307.001. Disponível em: https://nyaspubs.onlinelibrary.wiley.com/doi/full/10.1196/annals.1307.001. Acesso em: 22 abr. 2020.

DELIVORIAS, A.; SCHOLZ, N. Economic impact of epidemics and pandemics. [Bruxelas]: EPRS, 2020. Disponível em: https://www.europarl.europa.eu/RegData/etudes/BRIE/2020/646195/EPRS_BRI(2020)646195_ EN.pdf. Acesso em: 22 abr. 2020.

DENIS, M.; VANDEWEERD, V.; VAN DER VLIET, D. Overview of information available to support the development of medical countermeasures and interventions against COVID-19.

Transdisciplinary Insights - Living Paper, [S. I.], p. 1-120, 2020. Disponível em: https://www.apfh.pt/xfiles/scContentDeployer_pt/links/link92.pdf. Acesso em: 22 abr. 2020.

FAN, V. Y.; JAMISON, D. T.; SUMMERS, L. H. Pandemic risk: how large are the expected losses? Bulletin of the World Health Organization, [S. I.], n. 96, p. 129-134, 2018. 
FENG, Z. et al. The epidemiological characteristics of an outbreak of 2019 novel coronavirus diseases (COVID-19). China CDC Weekly, [S. I.], v. 2, n. 8, p. 113-122, 2020. Disponível em: https://pubmed.ncbi.nlm.nih.gov/32064853/. Acesso em: 22 abr. 2020.

GARRIDO, R. G.; GARRIDO, F. S. R. G. COVID-19: um panorama com ênfase em medidas restritivas de contato interpessoal. Interfaces Científicas - Saúde e Ambiente, [S. I.], v. 8, p. 127-141, 2020.

GE, X. Y. et al. Isolation and characterization of a bat SARS-like coronavirus that uses the ACE2 receptor. Nature, [S. I.], v. 503, n. 7477, p. 535-538, 2013.

GONZÁLEZ, J.M, et al. A comparative sequence analysis to revise the current taxonomy of the family coronaviridae. Archives of Virology, [S. I.], v. 148, n. 11, p. 2207-2235, 2001.

GORBALENYA, A. E. et al. The species severe acute respiratory syndrome-related coronavirus: classifying 2019-nCoV and naming it SARS-CoV-2. Nature Microbiology, [S. I.], v. 5, p. 536-544, 2020. DOI 10.1038/s41564-020-0695-z. Disponível em:

https://www.nature.com/articles/s41564-020-0695-z. Acesso em: 1 abr. 2020.

GUAN, Y. et al. Isolation and characterization of viruses related to the SARS coronavirus from animals in southern China. Science, [S. I.], v. 302, n. 5643, p. 276-278, 2003. Disponível em: https://science.sciencemag.org/content/302/5643/276. Acesso em: 22 abr. 2020.

INTERNATIONAL COMMITTEE ON TAXONOMY OF VIRUSES. News. [S. I.], 2020. Disponível em: https://talk.ictvonline.org/. Acesso em: 1 abr. 2020.

JONES, K. E. et al. Global trends in emerging infectious diseases. Nature, [S. I.], v. 451, n. 7181, p. 990-993, 2008.

KAKODKAR, P.; KAKA, N.; BAIG, M. N. A comprehensive literature review on the clinical presentation, and management of the pandemic coronavirus disease 2019 (COVID-19). Cureus, [S. I.], v. 12, n. 4, p. 1-18, 2020. DOI 10.7759/cureus.7560. Disponível em:

https://www.cureus.com/articles/29670-a-comprehensive-literature-review-on-the-clinicalpresentation-and-management-of-the-pandemic-coronavirus-disease-2019-covid-19. Acesso em: 22 abr. 2020.

KAMPF, G. et al. Persistence of coronaviruses on inanimate surfaces and their inactivation with biocidal agents. The Journal of Hospital Infection, [S. I.], v. 104, n. 3, p. 246-251, 2020. DOI 10.1016/j.jhin.2020.01.022. Disponível em:

https://www.journalofhospitalinfection.com/article/S0195-6701(20)30046-3/fulltext. Acesso em: 22 abr. 2020.

KLENK, H. D. et al. Host cell proteases controlling virus pathogenicity. Trends in Microbiology, [S. I.], v. 2, p. 39-43, 1994. 
LEE, G. O. M.; WARNER, M. The impact of SARS on China's human resources: implications for the labour market and level of unemployment in the service sector in Beijing, Guangzhou and Shanghai. The International Journal of Human Resource Management, [S. I.], v. 17, p. 860-880, 2006. DOI 10.1080/09585190600640919. Disponível em: https://www.tandfonline.com/doi/full/10.1080/09585190600640919. Acesso em: 22 abr. 2020.

LI, Q. et al. A simple laboratory parameter facilitates early identification of COVID-19 patients. MedRxiv, [S. I.], p. 1-6, 2020. DOI 10.1101/2020.02.13.20022830. Disponível em: https://www.medrxiv.org/content/10.1101/2020.02.13.20022830v1. Acesso em: 22 abr. 2020.

LI, W. et al. Bats are natural reservoirs of SARS-like coronaviruses. Science, [S. I.], v. 310, n. 5748, p. 676-679, 2005. DOI 10.1126/science.1118391. Disponível em: https://science.sciencemag.org/content/310/5748/676. Acesso em: 22 abr. 2020.

LIU, Y. et al. Clinical and biochemical indexes from 2019-nCoV infected patients linked to viral loads and lung injury. Sci China Life Sci, [S. I.], v.63, n. 3, p. 364-374, 2020. DOI 10.1007/s11427020-1643-8. Disponível em: https://link.springer.com/article/10.1007/s11427-020-1643-8. Acesso em: 22 abr. 2020.

LU, H. Drug treatment options for the 2019-new coronavirus (2019-nCoV). BioScience Trends, [S. I.], v. 14, n. 1, p. 69-71, 2020. DOI 10.5582/bst.2020.01020. Disponível em: https://www.jstage.jst.go.jp/article/bst/14/1/14_2020.01020/_article. Acesso em: 22 abr. 2020.

LWCF. Return on the investment from the land and water conservation fund: a report by the trust for public land. Boston: The Trust for Public Land, 2010. Disponível em: http://cloud.tpl.org/pubs/benefits-LWCF-ROI\%20Report-11-2010.pdf. Acesso em: 28 abr. 2020.

MCINTOSH, K. Coronaviruses: a comparative review. Current Topics in Microbiology and Immunology, [S. I.], v. 63, p. 85-129, 1974.

NEGRI, E. M. et al. Heparin therapy improving hypoxia in COVID-19 patients - a case series. MedRxiv, [S. I.], p. 1-15, 2020. DOI 2020.04.15.20067017. Disponível em: https://www.medrxiv.org/content/10.1101/2020.04.15.20067017v3. Acesso em: 22 abr. 2020.

NOVEL CORONAVIRUS PNEUMONIA EMERGENCY RESPONSE EPIDEMIOLOGY TEAM. The epidemiological characteristics of an outbreak of 2019 novel coronavirus diseases (COVID-19) in China. Chin J Epidemiol, [S. I.], v. 41, n. 2, p. 145-151, 2020.

PIKE, J. et al. Economic optimization of a global strategy to reduce the pandemic threat. PNAS, [S. I.], v. 111, n. 52, p. 18519-18523, 2014. DOI 10.1073/pnas.1412661112. Disponível em: https://www.pnas.org/content/111/52/18519. Acesso em: 22 abr. 2020.

QIU, W. et al. The impacts on health, society, and economy of SARS and H7N9 outbreaks in China: a case comparison study. Journal of Environmental and Public Health, [S. I.], p. 1-8, 2018. DOI 10.1155/2018/2710185. Disponível em: https://www.hindawi.com/journals/jeph/2018/2710185/. Acesso em: 22 abr. 2020. 
SANDS, P. et al. Assessment of economic vulnerability to infectious disease crises. The Lancet, [S. I.], v. 388, p. 2443-2448, 2016. DOI 10.1016/S0140-6736(16)30594-3. Disponível em: https://www.thelancet.com/journals/lancet/article/PIIS0140-6736(16)30594-3/fulltext. Acesso em: 22 abr. 2020.

SILVEIRA, J. A. G.; D'ELIA, M. L. Medicina da conservação: a ciência da saúde do ecossistema. Cadernos Técnicos de Veterinária e Zootecnia (UFMG), Minas Gerais, v. 72, p. 16-27, 2014.

SMITH, R. D. Responding to global infectious disease outbreaks: lessons from SARS on the role of risk perception, communication and management. Social Science \& Medicine, [S. I.], v. 63, n. 12, p. 3113-3123, 2006. DOI 10.1016/j.socscimed.2006.08.004. Disponível em: https://www.sciencedirect.com/science/article/pii/S0277953606004060?via\%3Dihub. Acesso em: 1 abr. 2020.

STEINHAUER, D. A. Role of hemagglutinin cleavage for the pathogenicity of influenza virus. Virology, [S. I.], v. 258, p. 1-20, 1999.

TAN, W. et al. Notes from the field: a novel coronavirus genome identified in a cluster of pneumonia cases-Wuhan, China 2019-2020. China CDC Weekly, [S. I.], v. 2, n. 4, p. 61-62, 2020.

UNDP. A socio-economic impact assessment of the Zika Virus in Latin America and the caribbean: with a focus on Brazil, Colombia and Suriname. New York: UNDP, 2017. Disponível em: https://www.undp.org/content/dam/rblac/docs/Research\%20and\%20Publications/HIV/UNDPRBLAC-Zika-English-WEB.pdf. Acesso em: 28 abr. 2020.

VAN DOREMALEN, N. et al. Aerosol and surface stability of SARS-CoV-2 as compared with SARSCoV-1. New England Journal of Medicine, [S. I.], v. 16, n. 382, p. 1564-1567, 2020. DOI 10.1056/NEJMc2004973. Disponível em: https://www.nejm.org/doi/10.1056/NEJMc2004973. Acesso em: 22 abr. 2020.

WALLS, A. C. et al. Structure, function and antigenicity of the SARS-CoV-2 spike glycoprotein. BioRxiv, [S. I.], p. 1-34, 2020. DOI 10.1101/2020.02.19.956581. Disponível em: https://www.biorxiv.org/content/10.1101/2020.02.19.956581v1. Acesso em: 1 abr. 2020.

WAN, Y. et al. Receptor recognition by the novel coronavirus from Wuhan: an analysis based on decade-long structural studies of SARS coronavirus. Journal of Virology, [S. I.], v. 94, n. 7, 2020. DOI 10.1128/JVI.00127-20. Disponível em: https://jvi.asm.org/content/94/7/e00127-20. Acesso em: 1 abr. 2020.

WANG, N. et al. Structure of MERS-CoV spike receptor-binding domain complexed with human receptor DPP4. Cell Research, [S. I.], v. 23, n. 8, p. 986-93, 2013. DOI 10.1038/cr.2013.92. Disponível em: https://www.nature.com/articles/cr201392. Acesso em: 1 abr. 2020. 
WEISS, S. R.; NAVAS-MARTIN, S. Coronavirus pathogenesis and the emerging pathogen severe acute respiratory syndrome coronavirus. Microbiology and Molecular Biology Reviews, [S. I.], v. 9, n. 4, p. 635-664, 2005.

WHO. Coronavirus disease (COVID-19): situation report - 122. [Genebra]: WHO, 2020a. Disponível em: https://www.who.int/docs/default-source/coronaviruse/situationreports/20200521-covid-19-sitrep-122.pdf?sfvrsn=24f20e05_2. Acesso em: 22 maio 2020.

WHO. Statement on the second meeting of the International Health Regulations (2005) Emergency Committee regarding the outbreak of novel coronavirus (2019-nCoV). Geneva: WHO, 2020b. Disponível em: https://www.who.int/news-room/detail/30-01-2020-statementon-the-second-meeting-of-the-international-health-regulations-(2005)-emergency-committeeregarding-the-outbreak-of-novel-coronavirus-(2019-ncov). Acesso em: 25 mar. 2020.

WHO. DRAFT landscape of COVID-19 candidate vaccines - 20 April 2020. [Genebra]: WHO, 2020c. Disponível em: https://www.who.int/blueprint/priority-diseases/key-action/novelcoronavirus-landscape-ncov.pdf?ua=1. Acesso em: 25 mar. 2020.

WORLD BANK GROUP. Pandemic emergency financing facility. [S. I.], 2019. Disponível em: https://www.worldbank.org/en/topic/pandemics/brief/pandemic-emergency-financingfacility?cid=EXT_WBSocialShare_EXT. Acesso em: 25 abr. 2020.

WRAPP, D. et al. Cryo-EM structure of the 2019-nCoV spike in the prefusion conformation. Science, [S. I.], v. 367, n. 6483, p. 1260-1263, 2020.

WU, Y. et al. SARS-CoV-2 is an appropriate name for the new coronavirus. The Lancet, [S. I.], v. 395, n. 10228, p. 949-950, 2020. Disponível em:

https://www.thelancet.com/journals/lancet/article/PIIS0140-6736(20)30557-2/fulltext. Acesso em: 22 abr. 2020.

YAO, H. et al. Patient-derived mutations impact pathogenicity of SARS-CoV-2. MedRxiv, [S. I.], p. 1-57, 2020. DOI 10.1101/2020.04.14.20060160. Disponível em:

https://www.medrxiv.org/content/10.1101/2020.04.14.20060160v2. Acesso em: 22 abr. 2020.

ZHOU, P. et al. A pneumonia outbreak associated with a new coronavirus of probable bat origin. Nature, [S. I.], v. 579, p. 270-273, 2020.

Recebido em: 28/04/2020

Aceito em: $24 / 05 / 2020$ 